\title{
Research on Information Fusion Strategy of Animal Husbandry Ecological Management Platform
}

\author{
Jing $\mathrm{Fu}^{1}$, Jian $\mathrm{Wu}^{1}$, Dan Wang ${ }^{1}$, Hongmei Luo ${ }^{1}$ \\ ${ }^{1}$ College of business administration, Wuhan Business University, Wuhan, 430079
}

Keywords: Animal husbandry; information integration; ecological engineering; countermeasures

\begin{abstract}
Starting from the actual background of animal husbandry as an important basic industry of social economy, the information fusion industry alliance member enterprises build the industry knowledge base in the process of building livestock ecological management platform. This paper takes into account the uncertainty of competition or cooperation among members, which requires a game analysis involving some participants in the process. The purpose is to guide and improve the theory of ecological engineering in china. According to the results of the analysis, this paper gives a series of corresponding management inspiration.
\end{abstract}

\section{Introduction}

In the process of national innovation and development, environmental protection awareness gradually increased, and ecological development of animal husbandry industry is the inevitable choice for the future of the enterprise. The application of eco-engineering development model in livestock husbandry industry will help its industry to meet the development needs of the times and realize the sustainable development mode. In this paper, theoretical research and countermeasure research on the construction of animal husbandry ecosystem management platform are of great significance to popularization and application of its theoretical system [1-3].

\section{Game process of information fusion in animal husbandry}

In the general process of externalizing the knowledge of livestock husbandry members and entering the livestock husbandry knowledge base, the necessary conditions for forming a livestock husbandry union are: common interests among member enterprises, and knowledge base of member enterprises is almost the same in a certain field or similar knowledge or information [4, 5]. Because the information between member enterprises in reality is asymmetric and imitates each other, this article uses evolutionary game theory to analyze the behavior decision-making of enterprises and enterprises in the process of information integration and information, and finally draw some suggestions to promote and improve the integration services management strategy [6].

\section{The basic hypothesis of investment game model}

By establishing a static game model of complete information, this paper makes some theoretical explanations for the game relationship between enterprises A, B and the government in the process of animal husbandry ecological platform construction. Basic assumptions of the model: (1) the model is only an enterprise A and an enterprise B as well as a government organization, which is considerable strength; (2) the model is the theoretical basis of Matthew effect model and reward system based on the new classical economics; (3) assume that the enterprise A takes into account the spill over effect and positive externalities of the hardware facilities of the knowledge base, while the enterprise B seldom considers this utility; (4) the enterprise A and enterprise B are "rational people", will maximize their profits; (5) the information between the enterprise A and the 
enterprise B is complete, and the game strategy and action of each other can be observed, that is, the "complete information" and the model is static; (6) the government incentive mechanism for enterprises not considering the effect of function; (7) the utility function of enterprise from the Cobb -Douglas form [7-9].

\section{Symbol specification}

$C_{A}$ : representing enterprise $\mathrm{A}$;

$C_{B}$ : representing enterprise $\mathrm{B}$;

$E$ : representing the knowledge base software investment level;

$G$ : representing the central government;

$I$ : representing the knowledge base hardware resources investment level;

$E_{A}$ : representing the enterprise $A$ investment to build the knowledge base of software resources;

$E_{B}$ : representing the enterprise B investment to build the knowledge base of software resources;

$E_{G}$ : representing the central government investment to build the knowledge base of software resources

$I_{A}$ : representing the enterprise A investment in knowledge base of hardware resources;

$I_{B}$ : representing the enterprise B investment in knowledge base of hardware resources;

$I_{G}$ : representing the central government to invest in the knowledge base of hardware resources;

$U_{A}=\left(I_{A}+I_{B}+I_{G}\right)^{\gamma}\left(E_{A}+E_{B}+E_{G}\right)^{\beta}$ represents the utility function for enterprise A;

$\gamma$. enterprise A considers the external utility parameters of knowledge base hardware facilities resources;

$\beta$ : enterprise A considers the external utility parameters of knowledge base software facility resources;

$U_{B}=\left(I_{A}+I_{B}+I_{G}\right)^{\alpha}\left(E_{A}+E_{B}+E_{G}\right)^{\beta}$ represents utility function for enterprise B;

$\alpha$ : the external utility parameters of the knowledge base hardware facility resources of the enterprise $\mathrm{B}, \quad 0<\alpha, \quad \beta, \quad \gamma<1, \quad 0<\alpha+\beta \leq 1, \quad 0<\gamma+\beta \leq 1$ and $\alpha \leq \gamma$;

$I_{G}=a I_{A}+b I_{B}, E_{G}=a E_{A}+b E_{B}$ : the more enterprises A and enterprise B invest more resources, the government will increase investment resources for these projects;

$a$ : the elastic coefficient between enterprise A to the project investment and government investment;

$b$ : the elastic coefficient between enterprise $\mathrm{B}$ to the project investment and government investment;

$R_{B}\left(I_{A}\right)$ : describes the input amount of infrastructure resources of a given enterprise $\mathrm{A}$ and how 
the enterprise B should react, so it is called the reaction function of enterprise B;

$R_{A}\left(I_{B}\right)$ : describes the input amount of infrastructure resources of a given enterprise B and how the enterprise A should react, so it is called the reaction function of enterprise A;

$B_{A}$ : the total budget for the enterprise A subject resource allocation;

$B_{B}$ : the total budget for the enterprise B subject resource allocation.

Under the above assumptions, we implicitly assume that the equilibrium exists, and only. In fact, not any game of Nash equilibrium exists, and even if there is not necessarily unique. To meet the model of stable equilibrium exists and only one condition is that the utility function is strictly concave $[10,11]$. The reaction function $R_{B}\left(I_{A}\right)$ and $R_{A}\left(I_{B}\right)$ are continuous functions with negative slopes, and the curve $R_{A}\left(I_{B}\right)$ is steeper than $R_{B}\left(I_{A}\right)$.

\section{Investment game expansion model}

\subsection{Establishment of extended model}

In this game, the revenue function of enterprise $\mathrm{A}$ and enterprise $\mathrm{B}$ is $U_{A}$ and $U_{B}$ respectively:

$$
\begin{aligned}
& U_{A}=\left(I_{A}+I_{B}+I_{G}\right)^{\gamma}\left(E_{A}+E_{B}+E_{G}\right)^{\beta} \\
& U_{B}=\left(I_{A}+I_{B}+I_{G}\right)^{\alpha}\left(E_{A}+E_{B}+E_{G}\right)^{\beta}
\end{aligned}
$$

In the formula, $0<\alpha, \beta, \gamma \leq 1,0<\alpha+\beta \leq 1, \quad 0<\gamma+\beta \leq 1$. Because enterprise A takes into account the spillover effects and positive externalities of building knowledge infrastructure hardware, enterprise B rarely considers this utility, therefore $\alpha \leq \gamma$. The goal of enterprise A is to maximize its utility function under the premise of meeting budget constraint. Then, the problem that enterprise A needs to solve is $P_{3}$ :

$$
\begin{gathered}
\mathrm{P}_{3}: \max _{\left\{E_{A}, I_{A}\right\}} U_{A}=\left(I_{A}+I_{B}+I_{G}\right)^{\gamma}\left(E_{A}+E_{B}+E_{G}\right)^{\beta} \\
\text { s.t. } E_{A}+I_{A} \leq B_{A}, E_{A} \geq 0, I_{A} \geq 0
\end{gathered}
$$

The problem that enterprise B needs to solve is $P_{4}$ :

$$
\begin{gathered}
\mathrm{P}_{4}: \max _{\left\{E_{B}, I_{B}\right\}} U_{B}=\left(I_{A}+I_{B}+I_{G}\right)^{\alpha}\left(E_{A}+E_{B}+E_{G}\right)^{\beta} \\
\text { s.t. } E_{B}+I_{B} \leq B_{B}, E_{B} \geq 0, I_{B} \geq 0
\end{gathered}
$$

The establishment of assumed budget constraint equation (i.e., all can be used to establish the knowledge base of investment resources). The first-order solution of the above optimization problem of $P_{3}$ and $P_{4}$ is: 


$$
\left\{\begin{array}{l}
I_{A}{ }^{*}=\max \left\{\frac{\gamma}{(\gamma+\beta)(1+a)}\left[(1+a) B_{A}+(1+b) B_{B}\right]-\frac{\gamma(1+b)}{(1+a)} I_{B}, 0\right\} \\
I_{B}{ }^{*}=\max \left\{\frac{\alpha}{(\alpha+\beta)(1+b)}\left[(1+a) B_{A}+(1+b) B_{B}\right]-\frac{\alpha(1+a)}{(1+b)} I_{A}, 0\right\}
\end{array}\right.
$$

Two reaction function formulas are defined in the formula:

$$
\left\{\begin{array}{l}
I_{A}^{*}=R_{A}\left(I_{B}\right) \\
I_{B}^{*}=R_{B}\left(I_{A}\right)
\end{array}\right.
$$

The reaction function group implies that the optimal strategy of the enterprise $A$ is the function of the enterprise $\mathrm{B}$, and vice versa. The enterprise $\mathrm{B}$ in every increase of knowledge base on the hardware facilities investment of 1 units, the optimal investment enterprise A to reduce the $\frac{\gamma(1+b)}{(1+a)}$ units; similarly, the enterprise A in every increase of knowledge base on the hardware facilities investment of 1 units, the optimal investment enterprise B reduced $\frac{\alpha(1+a)}{(1+b)}$ units.

\subsection{Solution of extended model}

Make the $M=(1+a) B_{A}+(1+b) B_{B}, \quad N=\frac{1+a}{1+b}$ in the formula, then:

$$
\left\{\begin{array}{l}
{I_{A}}^{*}=\max \left\{\frac{\gamma}{(\gamma+\beta)(1+a)} K-\frac{\gamma}{N} * I_{B}, 0\right\} \\
I_{B}{ }^{*}=\max \left\{\frac{\alpha}{(\alpha+\beta)(1+b)} K-\alpha N * I_{A}, 0\right\}
\end{array}\right.
$$

Because $D=\left|\begin{array}{cc}1 & \frac{\gamma}{N} \\ \alpha * N & 1\end{array}\right|, D_{1}=\left|\begin{array}{cc}\frac{\gamma * M}{(\gamma+\beta)(1+a)} & \frac{\gamma}{N} \\ \frac{\alpha * M}{(\alpha+\beta)(1+b)} & 1\end{array}\right|, \quad D_{2}=\left|\begin{array}{cc}1 & \frac{\gamma * M}{(\gamma+\beta)(1+a)} \\ \alpha * N & \frac{\alpha * M}{(\alpha+\beta)(1+b)}\end{array}\right|$

Then the solution of the formula can be written:

$$
\begin{aligned}
& I_{A}^{*}=\frac{D_{1}}{D}=\frac{\gamma * M}{(1-\alpha * \gamma)(\gamma+\beta)(1+a)}-\frac{\alpha * \gamma * M}{(1-\alpha * \gamma)(\alpha+\beta)(1+b)} \\
& I_{B}^{*}=\frac{D_{2}}{D}=\frac{\alpha * M}{(1-\alpha * \gamma)(\alpha+\beta)(1+b)}-\frac{\alpha * M * \gamma * N}{(1-\alpha * \gamma)(\gamma+\beta)(1+a)}
\end{aligned}
$$

\section{Summary of investment game model}

The construction of animal husbandry ecological management platform and information integration strategy will become the inevitable hot spot of the future development of social animal husbandry. The construction and application of animal husbandry ecological management platform can bring more lasting and healthy economic development for animal husbandry, and change the development status of traditional animal husbandry. It can improve the damage to the natural environment and the low yield model, and promote the realization of the strategy of ecological 
sustainable development.

Acknowledgements:

Study on the Strategies of Resource Mashups of Building Information Platform of Fresh Agricultural Products supported by $\mathrm{PhD}$ research fund of Wuhan Business Univeristy (NO.2016KB004)

\section{References}

[1] Choi I H, Lee H J, Kim D H, et al. Evaluation of Probiotics on Animal Husbandry and Environmental Management as Manure Additives to Reduce Pathogen and Gas Emissions in Pig Slurry[J]. 2015, 24(1):25-30.

[2] Zuo L J, Amp E. Research on voluntary environmental managements of animal husbandry leading enterprise-Taking the example of Dong Jin Nong $\mathrm{Mu}$ company[J]. Guangdong Agricultural Sciences, 2014.

[3] Liu Y. Research on the Teaching Reform of Animal Husbandry and Veterinary Speciality in Secondary Vocational Colleges Based on the Micro Class Technology[J]. Jiangsu Science \& Technology Information, 2016.

[4] Zhu Y, Li S. Research on Coordinated Development Between Animal Husbandry and Ecological Environment Protection in Australia[C]// International Conference on Computer and Computing Technologies in Agriculture. Springer International Publishing, 2015:285-291.

[5] Zhu Y, Li S. Research on Coordinated Development Between Animal Husbandry and Ecological Environment Protection in Australia[M]// Computer and Computing Technologies in Agriculture IX. Springer International Publishing, 2015:285-291.

[6] Krastev K. Ecological trends at animal husbandry nitrogen utilization.[J]. Biotechnology in Animal Husbandry, 2015, 31(1):1-12.

[7] Zhao H, Wu J, Zhang J, et al. Study on Environmental Monitoring System Based on Internet of Animal Husbandry Things[C]// International Conference on Materials Engineering, Manufacturing Technology and Control. 2016.

[8] Elliott S, Bendrey R, Whitlam J, et al. Preliminary ethnoarchaeological research on modern animal husbandry in Bestansur, Iraqi Kurdistan: Integrating animal, plant and environmental data[J]. Environmental Archaeology, 2015, 20(3):140925075715007.

[9] Xiong K N, Liu-Xing X U, Zhang J H, et al. Coupling Relationship between the Development of Ecological Animal Husbandry and the Control of Rocky Desertification in Karst Mountain Area[J]. Journal of Domestic Animal Ecology, 2016.

[10]Buerjin, Zhao S, He F, et al. SUSTAINABLE DEVELOPMENT STRATEGY STUDY ON XINJIANG'S GRASSLAND ANIMAL HUSBANDRY[J]. Chinese Journal of Agricultural Resources \& Regional Planning, 2014.

[11]Palapa N, Pron N, Ustymenko O. Industrial animal husbandry: environmental and economic consequences[J]. Balanced Nature Using, 2016, 4. 